\title{
Tradução e localização de jogos eletrônicos: o potencial criativo dos tradutores
}

\author{
Gabriel Albuquerque Ferreira* \\ Marileide Dias Esqueda ${ }^{* *}$
}

\begin{abstract}
Resumo
Os jogos eletrônicos são produtos artísticos que fazem parte de um mercado multibilionário em expansão, que superou a indústria da música e do cinema. $\mathrm{O}$ crescimento e a internacionalização desse mercado trouxeram a necessidade de localização, que representa uma grande oportunidade para tradutores que se interessam pela área de tradução de jogos eletrônicos. A partir do trabalho de tradução e localização do jogo Spelunky Classic HD no par linguístico inglês-português brasileiro, descrevemos e analisamos desafios importantes que o tradutor pode encontrar na localização de jogos eletrônicos e contribuímos com aportes teóricos e práticos que podem servir de apoio para futuros tradutores. Os desafios de natureza técnica e linguística demonstraram o quanto é importante que tradutores desenvolvam a criatividade, a capacidade de solucionar problemas e competências variadas que auxiliem na compreensão das características específicas da localização de jogos eletrônicos e na solução de todos os tipos de problemas linguísticos, culturais e técnicos.

Palavras-chave: Jogos eletrônicos. Videogames. Tradução e Localização. Tradução comentada. Spelunky Classic HD.
\end{abstract}

\footnotetext{
* Universidade Federal de Uberlândia, Tradutor Profissional, Graduando do Curso de Bacharelado em Tradução. http://orcid.org/0000-0003-0355-9152.

* Universidade Federal de Uberlândia, Doutora, Professora do Programa de Pós-Graduação em Estudos Linguísticos e do Curso de Bacharelado em Tradução. https://orcid.org/0000-0002-6941-7926.
}

Cadernos CESPUC de Pesquisa. Série Ensaios. n.38, $1^{\circ}$ Sem./2021, p. 174-200. e-ISSN: 2358-3231 (OJS). Recebido em: 30/06/2021. Aceito em: 31/08/2021. 


\title{
Game Translation and Localization: The creative Power of Translators
}

\author{
Gabriel Albuquerque Ferreira \\ Marileide Dias Esqueda
}

\begin{abstract}
Electronic games are artistic products that are part of an expanding multibillion dollar market that has surpassed the music and film industries. The growth and internationalization of this market have brought the need for localization, which represents a great opportunity for translators who are interested in the area of video game translation. Based on the translation and localization of a game called Spelunky Classic HD in the English-Brazilian Portuguese language pair, we describe and analyze important challenges that translators may encounter in the localization of video games, and contribute with theoretical and practical input that can serve to support future translators. The technical and linguistic challenges have demonstrated how important it is for translators to develop creativity, problem-solving abilities, and other skills that help in understanding the specific characteristics of video game localization and in solving all types of linguistic, cultural, and technical problems.
\end{abstract}

Keywords: Electronic games. Video games. Translation and Localization. Commented translation. Spelunky Classic HD.

Cadernos CESPUC de Pesquisa. Série Ensaios. n.38, 1º Sem./2021, p. 174-200. e-ISSN: 2358-3231 (OJS). Recebido em: 30/06/2021. Aceito em: 31/08/2021. 


\section{Introdução}

O mercado de jogos eletrônicos tornou-se, nas últimas décadas, um dos mais lucrativos e dinâmicos, rivalizando, até mesmo, com a indústria do cinema. Dado o crescimento do setor, surgem cada vez mais oportunidades para os profissionais da tradução desempenharem seu trabalho no processo de localização de jogos eletrônicos. No entanto, os estudos sobre o tema ainda se encontram em um estágio incipiente, já que são contemplados por um número relativamente pequeno de pesquisas e publicações, quando comparados, sobretudo no Brasil, com sua significativa relevância cultural e econômica.

As práticas de tradução e localização no setor, por seu turno, carecem de mais investigações para que se compreenda a qualidade exigida pelos consumidores desse tipo de mídia de entretenimento. O português é uma língua que, até pouco tempo atrás, era desprezada pela maioria das distribuidoras e empresas de jogos eletrônicos nos processos de tradução e localização. Dessa forma, os consumidores eram obrigados a adquirir o produto original em inglês, mesmo sem terem conhecimento dessa língua. No entanto, esse panorama começou a mudar, já que um número crescente de empresas tem reconhecido a importância do mercado brasileiro em suas vendas internacionais (ESQUEDA, 2020).

A indústria dos jogos eletrônicos tornou-se multibilionária, especialmente nessa última década. A competição acirrada entre as grandes empresas, tais como Nintendo, Sony, Microsoft e Electronic Arts, fez com que o investimento na localização de jogos eletrônicos para o Brasil e em outras partes do mundo se tornasse uma tendência. As empresas que estão em maior contato com as necessidades dos consumidores tendem a conquistar fatias cada vez maiores do mercado (BERNAL-MERINO, 2015).

$\mathrm{Na}$ atualidade, o Brasil tornou-se um importante consumidor de jogos eletrônicos, com mais de 60 milhões de jogadores. Apesar desse número expressivo, o faturamento total com jogos ainda mantém o país oscilando entre a $10^{\mathrm{a}}$ e $15^{\mathrm{a}}$ posição mundial no que concerne ao faturamento total. Esses números demonstram que o potencial de crescimento no país da indústria de jogos eletrônicos ainda é muito grande (ESQUEDA, 2020). 
É nesse contexto que o trabalho dos tradutores para essa indústria adquire importância crucial. Entretanto, dada a incipiência das pesquisas sobre a tradução e localização de jogos eletrônicos, notamos que ainda há um longo caminho a percorrer, não só na busca por uma maior padronização das traduções, mas também no desenvolvimento de uma base teórica e metodológica que auxilie os tradutores na elaboração de trabalhos mais condizentes com o que os consumidores esperam.

Dessa forma, buscamos, a partir deste estudo, contribuir com um aporte teórico e prático que explora os desafios da tradução e localização de jogos eletrônicos. O viés prático aqui exposto consiste na descrição do processo da tradução e localização do jogo Spelunky Classic HD feita por nós, uma modificação do Spelunky Classic, um jogo de código aberto desenvolvido pelo criador estadunidense de jogos, Derek Yu. Buscamos descrever não apenas a tradução de textos, imagens e as adequações técnicas necessárias ao processo de localização, mas também analisar os desafios encontrados e evidenciar a importância do trabalho criativo do tradutor na busca por soluções tradutórias satisfatórias.

\section{Aportes teóricos}

Uma das primeiras questões que necessitam de direcionamento teórico, em nossa opinião, é o problema da diferenciação entre a tradução de jogos eletrônicos e o processo de localização. O que se nota é que, muitas vezes, a tradução e a localização são utilizadas como sinônimos, quando, na verdade, não é tão simples assim.

Grande parte do trabalho do tradutor concentra-se na tradução de linhas de textos (ou, em inglês, linguistic strings) retiradas do software de entretenimento, isto é, do jogo. É comum que os tradutores recebam as linhas já extraídas do jogo e prontas para a tradução. A localização, por outro lado, é um processo muito mais complexo e que envolve outras etapas em nível técnico e tecnológico.

Segundo O'Hagan e Mangiron (2013), a localização tornou-se uma prática bem estabelecida e reconhecida, sendo um processo industrial essencial às empresas que necessitam distribuir produtos em formato 
eletrônico de forma eficiente para todo o mundo. No entanto, essas autoras também afirmam que a falta de teorização sobre os fenômenos da localização é o que levou a uma ambiguidade na relação conceitual entre "localização" e "tradução". Adaptar um software para mercados internacionais é um trabalho relacionado à tradução, mas que envolve a solução técnica e tecnológica de diversos problemas, ou seja, a localização. A localização, para Dunne (2014):

[...] se estende para além da tradução do texto da interface do usuário, incluindo todas as exigências do mercado-alvo para a representação de dados culturalmente dependentes, os conjuntos de caracteres para representação digital de sistemas de escrita, as codificações que permitem o armazenamento e recuperação de dados em idiomas diferentes do inglês, regras de ordenação, formatos de data (MM/DD/AAAA, DD/MM/AAAA, AAAA/MM/DD etc.), formatos de hora, bem como calendários e separadores decimais (ponto ou vírgula), entre outros exemplos. ${ }^{1}$ (DUNNE, 2014, p. 148, tradução nossa).

Esses dados, que precisam ser observados na localização de softwares utilitários, também se aplicam aos jogos eletrônicos, que nada mais são do que softwares, porém destinados ao entretenimento. Localizar jogos eletrônicos significa torná-los linguística e culturalmente adequados a um locale (combinação do país ou região e língua) onde o mesmo será distribuído (FURLAN e ALTHOFF, 2014). Localização significa adaptar as características que de alguma forma façam os jogadores estrangeiros perceberem que aquele jogo eletrônico não foi concebido originalmente para eles. Ainda é importante ressaltar que a localização, muitas vezes, envolve alterações no código do software, a tradução de material promocional, de manuais e outros textos relacionados ao jogo, assim como seus processos de legendagem e dublagem (quando os há). Dessa forma, uma série de profissionais podem estar envolvidos nesse processo, desde programadores, a tradutores e atores, dentre outros.

Para fins de descrição, lidamos, neste estudo, com aspectos da programação de um jogo eletrônico, não apenas implementando a extração

\footnotetext{
1 Original em inglês: “[...] it extended beyond the translation of text in the user interface to include all target market requirements for culturally dependent representation of data, including character sets for the digital representation of writing systems, encodings to enable the storage and retrieval of data in languages other than English, collation rules, date formats (MM/DD/YYYY, DD/MM/YYYY, YYYY/MM/DD, etc.), time formats, as well as calendars and decimal separators (period or comma), to cite but a few examples".
}

Tradução e localização de jogos eletrônicos: o potencial criativo dos tradutores 
de suas linhas de texto, mas também observando e manipulando aspectos e limitações impostos pela codificação (linguagem de programação) e identificando, a partir da testagem do jogo traduzido, os problemas que precisam ser solucionados. Além das linhas de texto em si, faz-se necessário lidar com as fontes das letras, as limitações de espaço alocados aos textos e a presença de textos inseridos dentro de imagens. A tradução e a localização terão como objetivo tornar o jogo eletrônico adequado ao jogador brasileiro, observando-se os desafios que esse tipo de trabalho impõe. Portanto, entendemos que realizamos um trabalho tanto de tradução quanto de localização, que, nesse sentido, não são sinônimos (O'HAGAN e MANGINRON, 2013), mas se complementam.

No que concerne aos parâmetros para se avaliar a qualidade da localização e do trabalho do tradutor, muito se afirma sobre o objetivo de manter o que os pesquisadores denominam "the same look and feel" em relação ao produto original. A esse respeito, Bernal-Merino afirma:

Do ponto de vista da tradução, as versões localizadas precisam manter a mesma estética e sensação [the same look and feel] do jogo na língua de partida, com todas as suas características de diversão originais. Porém, diferenças culturais nos costumes e pontos de vista podem forçar mudanças nas versões localizadas. ${ }^{2}$ (BERNAL-MERINO, 2009, p. 243, tradução nossa).

Já Mangiron e O’Hagan (2006), na tradução de Galhardi (2013), afirmam:

A grande prioridade da localização de jogos é preservar a experiência do jogo para os consumidores, mantendo a "estética e sensação" do original. A missão do localizador é produzir uma versão que dê a impressão aos jogadores de ter sido produzida em sua própria linguagem, além de trazer uma diversão equivalente ao que os jogadores da versão original sentiram. Para isto, é crucial que os tradutores tenham familiaridade com o domínio dos jogos. Eles precisam conhecer blocos comuns de palavras utilizadas em jogos, elementos como sotaque e terminologia, o tipo de humor presente no jogo, utilização de piadas etc. Eles também precisam ter a capacidade de reconhecer alusões e referências intertextuais a outros gêneros da cultura popular global, como filmes e quadrinhos (GALHARDI, 2013, p. 75).

2 Original em inglês: "From the translation point of view, localised versions have to maintain the same look and feel as the source language game, with all its playful and original characteristics. But cultural differences in customs and points of view may force changes in the localised versions". 
A ideia de que precisamos preservar "the same look and feel" de um jogo eletrônico original nas suas versões localizadas advém, em parte, de um pensamento, ao nosso olhar, ultrapassado, que defende a total fidelidade à experiência original, como se isso fosse possível.

Segundo Souza (2013), a tradição anglo-americana sempre prezou por uma prática tradutória na qual o tradutor precisa se apagar e fazer sempre transparecer as palavras do autor com total fidelidade ao texto de partida. No entanto, considera-se, hoje em dia, que o ato de traduzir é, acima de tudo, um ato de criação, não sendo, portanto, uma mera transferência de uma língua para a outra. Ao aplicar esse pensamento à localização de jogos eletrônicos, percebe-se o quão problemática é a concepção de "the same look and feel". Aqui é importante frisar que, no contexto da localização de jogos eletrônicos, a "fidelidade" adquire um sentido diferente do que é tradicionalmente discutido nas teorias da tradução, pois não parte do pressuposto do texto de partida, mas sim, da experiência do jogo original (MANGIRON e O'HAGAN, 2006).

Nesse ponto, pode-se fazer uma comparação entre a tradução literária e a tradução de jogos eletrônicos. Com frequência, os jogos narram, como os textos literários, histórias complexas, com muitos diálogos e com o desenvolvimento minucioso e detalhista de cenários e personagens. Além disso, contêm muitos aspectos fortemente ancorados em especificidades culturais que não fazem sentido em todas as línguas, como as piadas, por exemplo. Nesse contexto, o trabalho do tradutor é o de interpretar o material original e recriá-lo em outra língua de acordo com a sua interpretação e com suas ideias acerca do material a ser traduzido, sem perder de vista suas responsabilidades e profissionalismo.

Segundo Arrojo (1986, p. 45),

A tradução de qualquer texto [...] será fiel não ao texto 'original', mas àquilo que consideramos ser o texto original, àquilo que consideramos constituí-lo, ou seja, à nossa interpretação do texto de partida que será, como já sugerimos, sempre produto daquilo que somos, sentimos e pensamos. (ARROJO, 1986, p. 45).

Rosemary Arrojo reforça, nesse trecho, a ideia da recriação que todo tradutor produz no texto que se propõe a traduzir, pois o texto traduzido é produto da interpretação que o tradutor faz do material original, uma interpretação que é única e influenciada pelas concepções pessoais do tradutor. 
É relevante notar ainda que, em The Game Localization Handbook (2012), Chandler e Deming afirmam que alguns jogos podem até mesmo ser mais brilhantes em suas versões traduzidas e localizadas do que nas originais, devido justamente ao talento que muitos tradutores têm para a escrita, a fabulação e a criação. Então, o que significa manter "the same look and feel"? Quem define o que e como é a experiência original? A experiência original pode até mesmo ser inferior à sua versão localizada. Na realidade, cada versão localizada é, por essência, um jogo único e diferente do original.

$\mathrm{O}$ tradutor necessita ser criativo e também aprender a lidar com uma série de problemas comuns nessa indústria, que podem afetar negativamente seu trabalho e impactar a qualidade da tradução. O tradutor de jogos normalmente tem acesso apenas a partes do texto e linhas de textos descontextualizadas, o que dificulta muito seu trabalho. Afinal,

Trabalhar um texto sem contexto não só complica o processo de decisão tradutória, como indiscutivelmente põe em questão a própria possibilidade de entender o texto como um todo e o ato pragmático de comunicação do qual é um artefato ostensivo. (DUNNE, 2020 [2015], p. 266).

É uma prática comum da indústria fornecer informações insuficientes e apenas arquivos de texto em planilhas do Excel para serem traduzidos. Geralmente, o tradutor nem ao menos recebe o localization kit que inclui o jogo e informações de contexto (CHANDLER; DEMING, 2012).

Diante do exposto, buscamos, na próxima seção, não apenas ilustrar os desafios enfrentados na tradução e localização, bem como nossas tentativas de recriação dos textos inseridos no jogo eletrônico Spelunky Classic HD.

\section{Descrição do jogo eletrônico Spelunky Classic HD e aspectos metodológicos}

O Spelunky Classic HD é um jogo de plataforma em 2D, nos mesmos moldes de clássicos como Super Mario World (1990) e Sonic the Hedgehog 
(1991). Além das características do gênero plataforma, ele também apresenta fortes características do gênero rogue-like, que se utiliza de elementos como a criação de fases por algoritmos procedurais e a morte permanente do personagem jogável, que força o jogador a reiniciar a jornada.

O jogo foi desenvolvido pelo já mencionado criador estadunidense de jogos, Derek Yu, na engine GameMaker para Windows e inicialmente lançado em 2008. Já em 2009, foi disponibilizado como um jogo freeware. Posteriormente, o jogo foi reconstruído na linguagem de programação $\mathrm{C}++$ e relançado com gráficos e desafios repaginados para as mais variadas plataformas, tais como computadores e consoles da série Xbox e PlayStation. A versão melhorada do Xbox Live Arcade foi lançada em 4 de julho de 2012. Esta versão também foi lançada para PC em 8 de agosto de 2013 e para PlayStation 3 em 27 e 28 de agosto de 2013. O jogo também foi lançado para PlayStation 4, em 7 de outubro de 2014, e conta com planos para lançamento no Nintendo Switch no verão do hemisfério norte de 2021. Além dessa versão, também existe uma continuação, intitulada Spelunky 2, para diversas plataformas.

Figura 1- Imagem principal do website do jogo eletrônico Spelunky

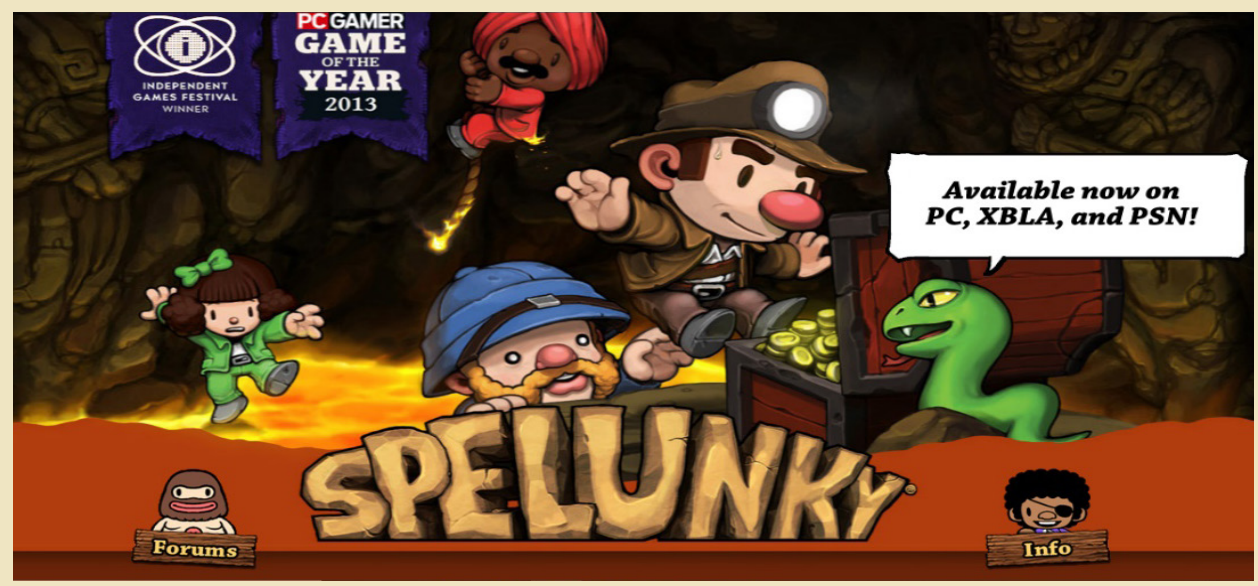

Fonte: Spelunky Classic, 2008

Desde então, esse jogo eletrônico angariou uma grande quantidade de fãs que criaram comunidades on-line, através das quais eles competem pelas melhores pontuações, pelos melhores tempos e estabelecem uma série de desafios a serem concluídos em jogo. 
O jogo, em sua versão de 2008, hoje comumente conhecido por Spelunky Classic, teve seu código-fonte liberado para uso público, em 25 de dezembro de 2009, o que permite que programadores manipulem e modifiquem esse código como uma forma de treinamento ou aprendizado e também para fornecer novas possibilidades de entretenimento à comunidade gamer que aprecia esse estilo clássico de jogos de plataforma.

Um dos desenvolvedores que trabalhou com esse código aberto (open source) foi Ivan Yancharkin, que disponibilizou na plataforma GitHub e na Itch.io sua modificação para o jogo, intitulada Spelunky Classic HD. É essa versão que foi tomada como objeto de estudo, tradução e localização no presente trabalho. Ela conta com traduções já terminadas do inglês para o espanhol e para o russo e, portanto, a tradução e localização aqui descritas envolvem, ineditamente, a tradução e localização para a língua portuguesa do Brasil.

Em Spelunky Classic HD, o jogador controla um espeleólogo que explora uma série de cavernas e enfrenta uma série de obstáculos, inimigos e situações aleatórias de alta dificuldade. $\mathrm{O}$ avatar que o jogador controla tem uma clara inspiração no personagem dos cinemas Indiana Jones, protagonista dos filmes Os caçadores da arca perdida (Raiders of the Lost Ark, 1981); Indiana Jones e o Templo da Perdição (Indiana Jones and the Temple of Doom, 1984); Indiana Jones e a última cruzada (Indiana Jones and the Last Crusade, 1989) e Indiana Jones e o Reino da Caveira de Cristal (Indiana Jones and the Kingdom of the Crystal Skull, 2008). Uma série de

[...] eventos clichê ligados a esse personagem podem ser disparados a qualquer momento do jogo: pedras podem rolar e fazer as estruturas da caverna desmoronarem; tesouros e damas em apuros podem ser levados ao final da fase para conseguir recompensas; sacrifícios podem ser oferecidos a deuses pagãos em troca de ajuda para os desafios que virão a seguir. (MUSSA, 2016, p. 9).

Na estética, nos eventos e nos personagens de Spelunky visualizamos a maneira como a intertextualidade permeia os jogos eletrônicos que se utilizam de uma série de tropos narrativos já estabelecidos na cultura e no imaginário popular. A intertextualidade pode

[...] ser entendida como textos que falam através de outros textos, como o reconhecimento explícito ou implícito da presença de um texto em outro texto. A intertextualidade pode ser constatada como uma possível alusão, às vezes, 
nem tão assim clara, para outros leitores. Refere-se, parcial ou integralmente, a outros textos. O processo intertextual ocorre e se situa no âmbito do leitor. Só o leitor, com seu conhecimento próprio, com a sua sensibilidade, pode constatar, gerenciar, perceber a presença ou não de outro ou outros textos no texto que lê. Trata-se da busca que o leitor ou o espectador poderá fazer quando, ao ler uma obra literária ou assistir a um filme, for provocado pelo reconhecimento de determinados elementos presentes em suas leituras anteriores. Trata-se de uma evocação particular e sensitiva desse receptor específico no seu ato particular de leitura. Na realidade, o leitor faz um passeio, incursionando pelas suas lembranças, promovendo associações textuais perceptíveis no universo do seu saber cultural. (CARDOSO, 2011, p. 6).

A intertextualidade, no entanto, não ocorre apenas dentro da literatura e do cinema. Em vários jogos eletrônicos, especialmente naqueles que não apresentam histórias complexas e bem desenvolvidas, os elementos narrativos situam as ações em jogo dentro de um mundo ficcional cuja construção depende de referências de natureza intertextual. O jogo em si fornece dicas que remetem a modelos familiares ao jogador dentro da cultura popular (KLEVJER, 2001, apud CRUZ, 2005). Esse é o caso da narrativa de Spelunky que, sem as referências intertextuais, perderia grande parte de seu significado. Ao ligarmos o jogo, imediatamente somos apresentados a um personagem explorador que carrega sempre seu chapéu e o chicote ao lado. A conexão com Indiana Jones é praticamente imediata.

\section{Figura 2 - Personagem Indiana Jones e arte do personagem principal do jogo Spelunky}
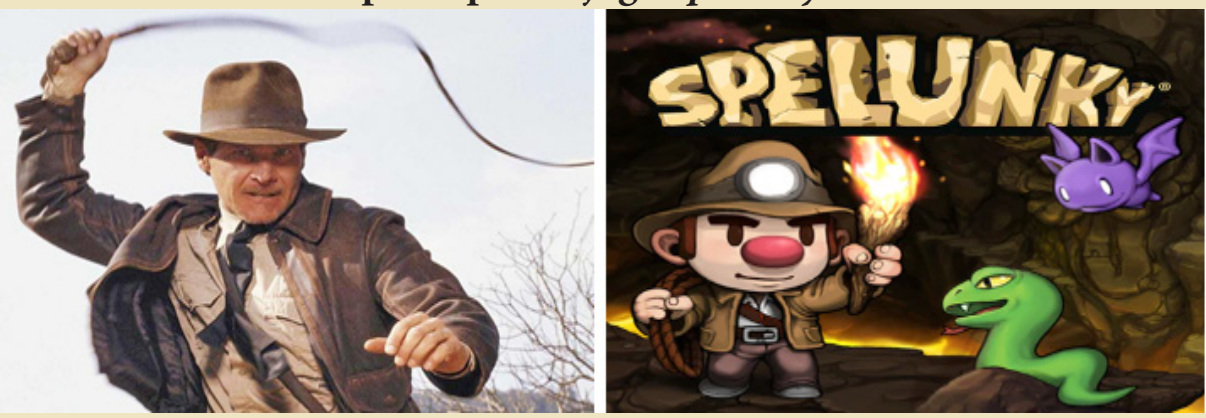

Fontes: Fontes: Google Imagens e Spelunky Classic 


\section{Figura 3 - Imagem do personagem principal do jogo Spelunky Classic HD explorando os perigos das cavernas}

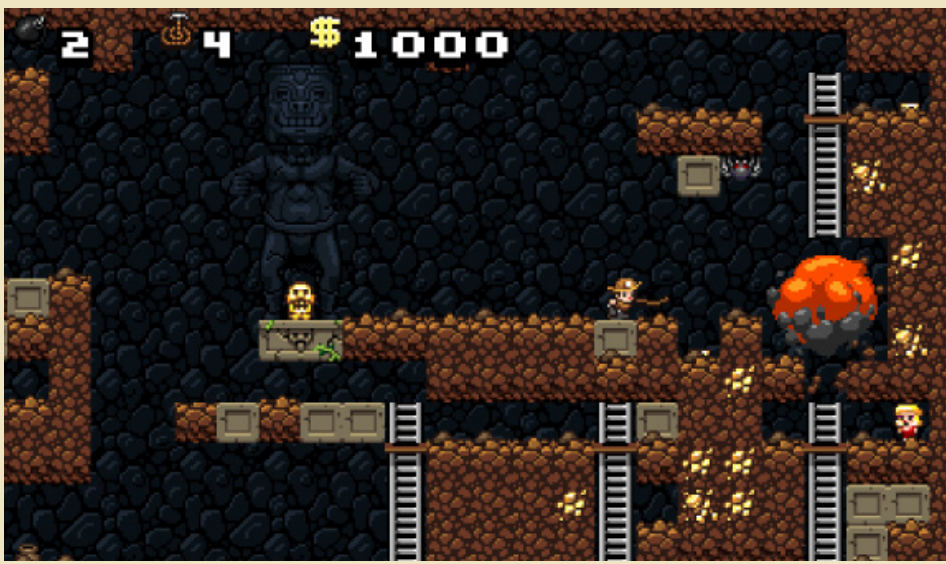

Fonte: Spelunky Classic HD

Em Spelunky Classic HD, o objetivo é percorrer os mapas em direção ao subterrâneo, para encontrar a saída que leva ao próximo nível do jogo. Cada nível conta com uma série de desafios, inimigos e armadilhas que se tornam progressivamente mais desafiadores à medida que o jogador avança. $\mathrm{O}$ personagem pode correr, pular, subir escadas e cordas e agarrar-se às beiradas das plataformas. Ele também pode pular na cabeça dos inimigos para derrotá-los, uma mecânica já bastante conhecida em jogos da série Super Mario, além de utilizar o chicote ou outros equipamentos para o ataque.

O jogo não conta com um sistema de salvamento. Uma vez que o jogador perca, ele deve reiniciar a jornada. Apenas ficam gravadas as pontuações e estatísticas acumuladas em jogo. No entanto, o jogo conta com uma mecânica de atalhos. Se o jogador avança pelo jogo, ele pode encontrar o Tunnel man, ou "Homem do túnel”, em nossa tradução. Ele permite, desde que o jogador entregue uma certa quantidade de moedas e itens, a criação de atalhos que possibilitam que certos níveis possam ser pulados em partidas subsequentes. Sobre os atalhos, Thompson (2015, p. 3) nos diz que:

O custo total de cada caminho varia com base em cada atalho e o pagamento é cumulativo ao longo do tempo, permitindo que o jogador eventualmente 
desbloqueie um determinado atalho se continuar a pagá-lo. Depois de construído, cada atalho é permanente e o jogador pode usá-lo no início de um novo jogo para evitar um ou mais mundos. No entanto, é importante observar que o uso desses atalhos torna a partida subsequente inválida para as pontuações da tabela de classificação. Assim, muitos desafios, tanto no próprio jogo Spelunky quanto na comunidade de jogadores, proíbem o uso de atalhos. (THOMPSON, 2015, p. 3 , tradução nossa). ${ }^{3}$

Além da mecânica dos atalhos, o jogador também pode encontrar lojistas em vários andares do subterrâneo. Cada um deles cuida de um tipo de loja que fornece recursos diferentes ao jogador, desde que sejam pagos com as moedas e tesouros. Esses itens, que podem ser comprados ou encontrados, são um dos maiores diferenciais entre Spelunky e outros jogos famosos do gênero plataforma. Os itens podem ser consumíveis, acessórios ou armas. Os itens consumíveis são aqueles que podem ser utilizados apenas uma vez. Os maiores exemplos são as bombas e as cordas que, nesse jogo, funcionam como "chaves" que possibilitam acesso a outras áreas inacessíveis somente com o pulo, uma vez que permitem ao jogador alcançar áreas elevadas ou destruir paredes ou pisos da caverna para permitir o avanço (THOMPSOM, 2015).

Por fim, temos as armas que devem ser carregadas pelo jogador e utilizadas quando necessário. Entre elas, temos o chicote, o facão, o arco e as flechas e a escopeta. Os jogadores também podem usar pedras e outros itens como armas improvisadas ao arremessá-los nos inimigos.

Outro elemento característico do jogo que deve ser mencionado é a geração de fases por algoritmos procedurais. Isso significa que cada nível é criado, de acordo com alguns critérios, de forma randômica. Isso faz com que cada partida do jogo seja diferente. Os níveis são criados no momento em que o jogador chega nele e então preenchidos com inimigos, armadilhas, lojas e desafios diferentes. Dessa forma, algumas partidas podem ser mais fáceis e outras mais desafiadoras. O jogador nunca sabe ao certo o que vai encontrar quando inicia uma partida e isso é muito relevante para o que é chamado na indústria de replayability ou rejogabilidade, um fator que define as chances de um jogo ser jogado mais de uma vez e por mais tempo.

\footnotetext{
3 Original em inglês: "The total cost of each path varies with each shortcut and payment is cumulative over time, allowing the player to eventually unlock a given shortcut if they continue to pay him. Once built, each shortcut is permanent and the player can use it at the beginning of a new game to avoid one or more worlds. However, it is important to note that using these shortcuts renders the subsequent play invalid for leaderboard scores. As such, many challenges both in the Spelunky game itself and within the player community forbid the use of shortcuts".
} 
Seguindo essa escolha de design, o jogo também apresenta, em alguns momentos, frases e nomes de NPCs (non-player character) randômicos, especialmente na tela de introdução e nas lojas encontradas nas fases. Como cada partida deve ser diferente, o jogo escolhe, aleatoriamente, frases e nomes de NPC quando o jogo é iniciado e quando os níveis são preenchidos. Essa característica é de grande importância e tem um impacto direto no processo de localização, gerando uma série de desafios.

Assim, nossa proposta foi traduzir e localizar, do inglês para o português do Brasil, o jogo Spelunky Classic HD, com o propósito de verificar e comentar seus desafios linguísticos e técnicos. Ainda que possua baixa densidade linguística, consideramos este trabalho inédito, pois o jogo não possui tradução e localização para a língua portuguesa, como já mencionado.

Embora seja escassa na literatura da área dos Estudos da Tradução a tradução comentada de jogos eletrônicos traduzidos e localizados para outras línguas, o presente estudo, de caráter descritivo, tem, como objetivo geral, comentar a tradução e localização realizadas com vista a discutir seus aspectos mais desafiadores. Não nos propomos a discutir as contribuições teóricas da tradução comentada (ZAVAGLIA et al., 2015), mas nos inspiramos em tal metodologia para teorizar sobre nossa prática, no sentido de produzir os comentários sobre as linhas de texto traduzidas. Desta forma, os comentários que construímos evidenciam e discutem nossas escolhas linguísticas e os percursos da localização do jogo em nível técnico e tecnológico, nossos dois objetivos específicos. Com tais propósitos em mente, consideramos que a tradução comentada nos auxiliou a aumentar a autoconsciência acerca da qualidade de nosso trabalho tradutório, bem como de todo o aparato técnico e tecnológico envolvido na tradução e localização do jogo eletrônico Spelunky Classic HD.

\section{Aportes práticos: Spelunky Classic Hd em $\mathrm{Pt}-\mathrm{Br}$}

O Spelunky Classic HD, disponibilizado no GitHub e no Itch.io pelo usuário "yancharkin", foi pensado, desde o princípio, de forma a facilitar o processo de localização. Essa foi uma preocupação do desenvolvedor. Por 
essa razão, não tivemos o trabalho adicional de procurar as linhas de texto dentro do código de programação. Além disso, o desenvolvedor elaborou um tutorial para auxiliar os voluntários nesse processo e disponibilizou-o tanto no GitHub quanto no Itch.io.

O GitHub é uma plataforma on-line na qual são hospedados códigosfonte de desenvolvedores. Nela, existem inúmeros projetos open source com os quais desenvolvedores iniciantes e demais usuários da plataforma podem colaborar. Já o Itch.io é um marketplace, no qual criadores independentes disponibilizam gratuitamente ou comercializam seus jogos eletrônicos. $\mathrm{O}$ Spelunky Classic HD pode ser encontrado nessas plataformas nos seguintes endereços: https://github.com/yancharkin/SpelunkyClassicHD e https:// yancharkin.itch.io/spelunky-classic-hd.

Um outro ponto muito positivo e facilitador na elaboração deste trabalho foi a possibilidade de contato direto com Ivan Yancharkin, que nos auxiliou em alguns momentos mais complexos do ponto de vista da programação.

O jogo pode ser baixado das plataformas em um arquivo compactado. Após sua extração, podemos visualizar o seguinte conteúdo em nosso diretório:

\section{Figura 4 - Diretório contendo os arquivos do jogo}

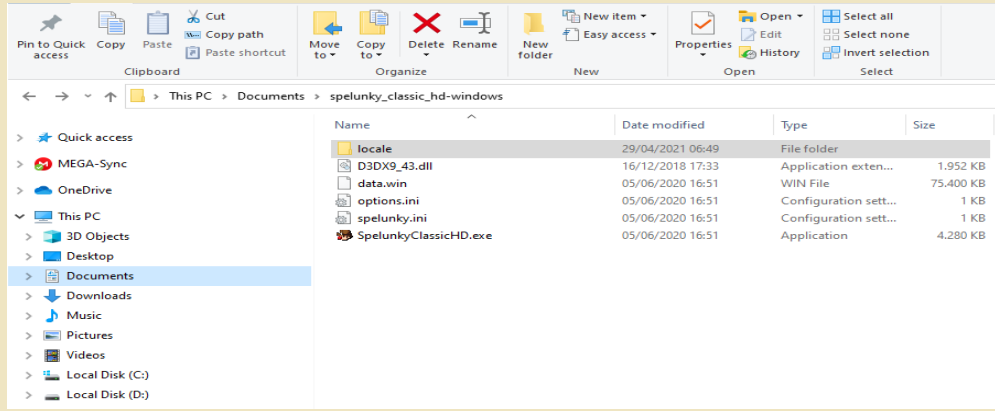

Fonte: arquivos dos autores

Nesse diretório (Figura 4), podemos visualizar arquivos da programação do jogo e um arquivo executável, com o nome "SpelunkyClassicHD.exe", que inicia o jogo. 
Figura 5 - Tela inicial do jogo eletrônico Spelunky Classic HD

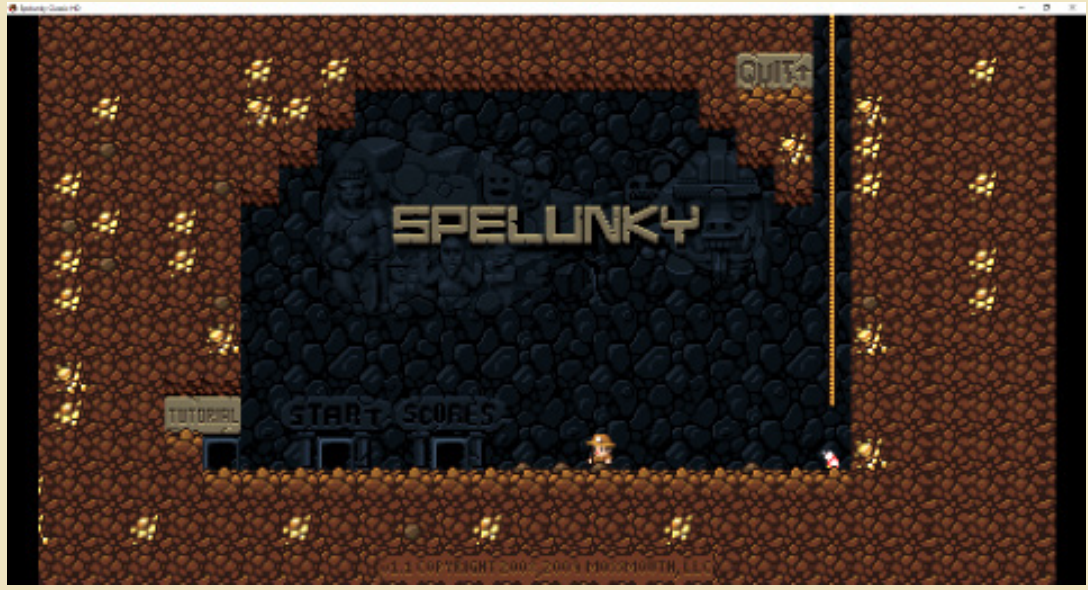

Fonte: Spelunky Classic HD

Como foi dito anteriormente, o desenvolvedor Ivan Yancharkin já trabalhou com o código dessa modificação do Spelunky de maneira a facilitar sua tradução e localização. $\mathrm{Na}$ indústria, esse processo é denominado como internacionalização, isto é, preparação técnica de produtos e materiais digitais de forma que possam receber versões para outras línguas (ESQUEDA, 2020). Todo o conteúdo linguístico do jogo pode ser observado e alterado a partir da manipulação dos arquivos dentro da pasta "locale" (Figura 4).

A primeira etapa no processo de localização do jogo é a manipulação do arquivo locales.json. Esse é o arquivo que controla as opções de línguas dentro do jogo, permitindo que o jogador possa alternar entre as opções disponíveis. Essa manipulação pode ser realizada com o software Notepad++, um editor de texto de código aberto, que está disponível gratuitamente para sistemas Windows. Esse é um programa simples, e de fácil utilização, já que permite a manipulação de códigos-fonte em diversas linguagens de programação. A figura a seguir mostra o Notepad++ com o arquivo locales.json aberto: 
Figura 6 - Arquivo locales.json aberto no Notepad++

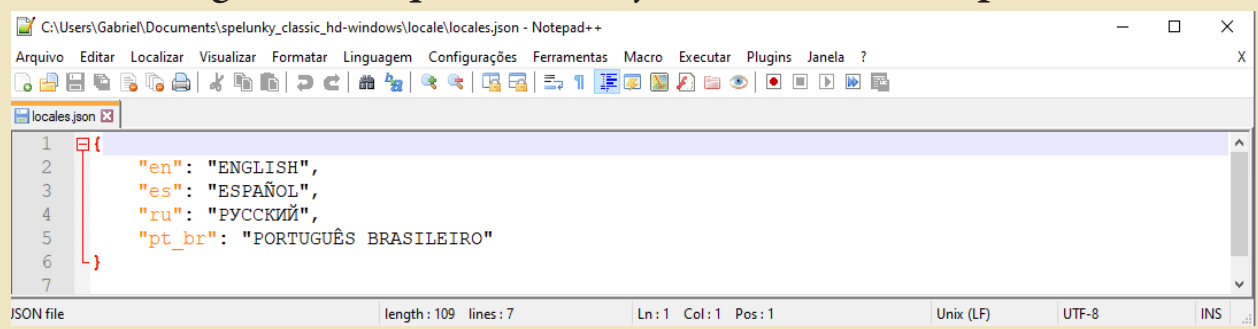

Fonte: arquivos dos autores

Como podemos notar, o arquivo já lista o inglês, o espanhol e o russo, respectivamente representados por "en", “es" e "ru”. Na cor laranja, vemos o código do jogo e, em preto e entre aspas, vemos o que será exibido na tela do jogo para o usuário. Para prosseguir, inserimos a linha 5 de programação adicional contendo o código "pt_br" e o texto "PORTUGUÊS BRASILEIRO". A partir desse momento, o português brasileiro passa a constar como uma das opções de línguas do jogo, mas as linhas de texto ainda precisam ser traduzidas para que a opção seja corretamente exibida no menu.

Em seguida, dentro da pasta "locales", criamos um diretório com o nome "pt_br". Esse é o diretório que deve conter as linhas de texto traduzidas, assim como as imagens do jogo e arquivos de fontes e caracteres disponíveis.

O próximo passo é entrar na pasta "en" que contém o arquivo text. json e copiá-lo para a nova pasta "pt_br". Esse é o arquivo que contém as linhas de texto do jogo. A partir dessa cópia com o texto original em inglês, podemos dar início ao trabalho de tradução das linhas de texto (linguistic strings).

Ao abrirmos o arquivo com o Notepad++, visualizamos a codificação e as linhas de texto. As primeiras 14 linhas são as correspondentes ao menu do jogo. Podemos vê-las, traduzidas por nós, na figura a seguir: 
Figura 7- Arquivo text.json aberto no Notepad++ com as linhas de texto traduzidas

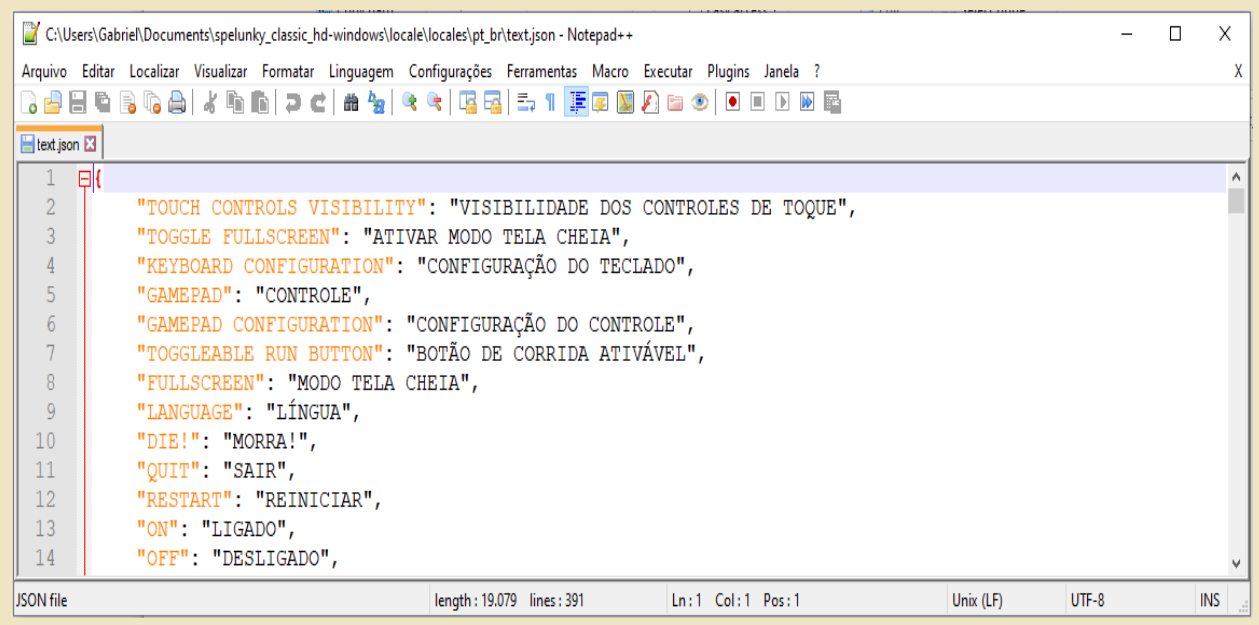

Fonte: arquivos dos autores

Nesse momento, já podemos começar a observar a tradução no próprio jogo. No menu, que pode ser acionado pressionando-se a tecla ESC, o português brasileiro já pode ser escolhido.

\section{Figura 8 - Parte do menu do jogo traduzido para o pt-br}

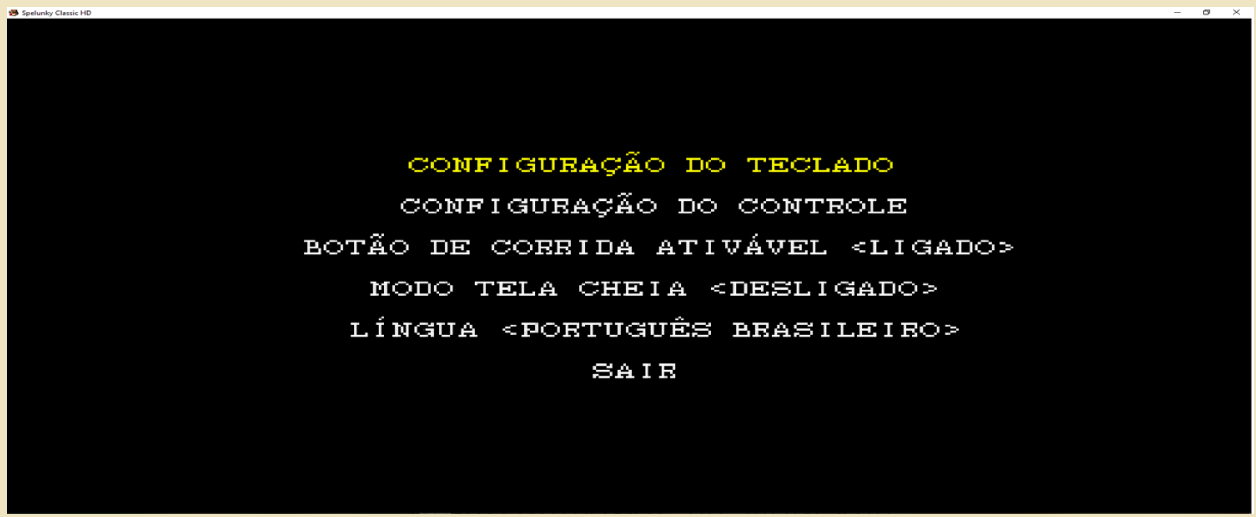

Fonte: arquivos dos autores

É importante mencionar que as primeiras versões da tradução foram sendo modificadas e aperfeiçoadas. Em se tratando de um jogo eletrônico, a localização envolve uma rigorosa etapa de testagem para identificar não 
apenas o contexto em que cada linha de texto é exibida em jogo, mas aspectos como espaço ocupado em tela e adequação à estética do jogo como um todo. Por esse motivo, por diversas vezes, tivemos de retornar ao arquivo text.json para fazer modificações e adequações das linhas traduzidas.

Ao todo foram traduzidas 388 linhas de texto, que dizem respeito ao menu e a todos os textos inseridos no jogo e que indicam as diversas ações do jogador. A título de ilustração, e por questões de espaço, descreveremos o processo de tradução de algumas delas.

Na linha de texto que se referia a " $A$ Shotgun”, optamos pela tradução "Uma Escopeta”, pois "escopeta" já é utilizada pelos jogadores brasileiros de forma corriqueira para se referir à arma que está presente em inúmeros jogos de tiro.

Com relação à linha "Your spider sense tingles!", optamos pela tradução “Seu sentido aranha começa a formigar!”. Nessa linha, observamos uma referência intertextual, neste caso ao Homem-Aranha, super-herói e personagem da Marvel Comic. Poderíamos utilizar uma expressão como "sexto-sentido", eliminando a referência, mas optamos pela tradução consagrada "sentido aranha", pois julgamos que o público (o jogador) brasileiro reconhece e tem apreço por referências a super-heróis, conforme explicado na segunda seção deste trabalho, a partir de O'Hagan e Mangiron (2006).

Em se tratando da linha "Kills", podemos dizer que tal palavra em inglês pode ter vários sentidos, inclusive podendo ser verbo ou substantivo. Em jogo, ela é utilizada para listar os inimigos que o jogador derrotou. A palavra "mortes", por exemplo, poderia ser uma opção, mas seria genérica e não traria ênfase para o papel do jogador. Por esse motivo, optamos pela tradução "abates" porque ela representa bem o trabalho ativo do jogador na morte dos inimigos.

Como o Spelunky Classic HD é um jogo rogue-like, a dificuldade acentuada é uma das características predominantes da jogabilidade. O jogador tem apenas uma "vida", apenas uma tentativa de tentar chegar ao final do jogo e, se falhar, voltará ao início. Com esse fator em mente, o desenvolvedor disponibilizou na página do jogo o link para sua versão debug. A versão debug tem a finalidade principal de facilitar a testagem do jogo. Como o tradutor e demais profissionais envolvidos com a testagem não dispõem de tempo para se aprofundar nas mecânicas como um jogador 
faria no jogo em sua versão final (“jogável”), a versão debug conta com ferramentas que facilitam o deslocamento do personagem e auxiliam os profissionais a visualizarem os diferentes cenários e situações do jogo em ação. No caso do Spelunky Classic HD, a versão debug oferece alguns recursos atrelados às teclas F2, F3 e F4 do teclado que realizam, respectivamente, as ações de transferir o jogador entre os níveis do jogo, abrir todos os atalhos e liberar todos os desafios. Para todos os outros efeitos, a versão debug é idêntica à versão “jogável”.

Como o processo de localização estende-se para além das linhas de texto (ESQUEDA, 2020; BERNAL-MERINO, 2015), em um próximo passo voltamos a atenção para as imagens que integram os cenários do jogo. Como dissemos, dentro da pasta "en" em "locales", estão contidos todos os arquivos de textos em língua inglesa. Nesse local, também podemos encontrar a pasta “images”, que contém arquivos de imagem na extensão “.png”. Esses são os arquivos que são utilizados pelo jogo na exibição de placas e outros detalhes do cenário. Copiamos, então, a pasta “images” contida no diretório da língua inglesa para a pasta da tradução "pt_br" e iniciamos um processo de edição manual das imagens em inglês para adequá-las ao português.

O Spelunky Classic HD é um jogo eletrônico que tem todo o seu aspecto visual elaborado na estética pixel art. Segundo Silber (2016), o estilo pixel art pode ser definido por um estilo artístico digital, no qual cada pixel visível de uma determinada imagem em tela é colocado em um local específico e de forma intencional. É um estilo apreciado por muitos jogadores, pois, ao mesmo tempo em que remete à nostalgia dos antigos jogos das décadas de 80 e 90, mantém-se contemporâneo e continua sendo utilizado em grandes títulos atuais, principalmente em jogos indies (jogos eletrônicos independentes). As imagens digitais são constituídas por pixels, mas o

[...] o pixel art se diferencia pela técnica e pelas ferramentas com que a imagem é configurada. Dessa forma, para se produzir pixel art é necessário ter controle artístico sobre cada pixel que compõe a imagem durante o processo de produção, aliado a uma limitada paleta de cores, revelando assim a natureza do pixel de forma explícita no resultado final. Devido à sua simplicidade em ressaltar o elemento mínimo constituinte da imagem, o pixel art possui fortes tendências à 
baixa resolução gráfica e foi largamente utilizado no passado devido às restrições técnicas que o videogame sofreu em seu início. (SARMENTO; OLIVEIRA; MAFRA; NEVES, 2016, p. 57)

O pixel art, apesar de poder ser usado para formar grandes e complexas imagens, apresenta algumas facilidades, especialmente quando lidamos com pequenos detalhes do cenário. Foi esse fator que facilitou a edição das imagens de Spelunky Classic HD. Com o aplicativo gratuito Paint 3D, disponibilizado pela Microsoft, foi possível abrir e editar cada um dos arquivos na extensão "PNG". A seguir, temos a versão original de uma placa do cenário, que permite apagar o placar de pontuação do jogador, representada pelo arquivo "reset_sign.png" (lado esquerdo da Figura 9). A partir dessa imagem original, apagamos o conteúdo escrito utilizando a ferramenta de conta gotas para copiar a tonalidade de fundo e cobrir a palavra com alguns dos pincéis do aplicativo. O conta gotas nos permitiu copiar as cores originais e a ferramenta "Caneta de pixel" nos permitiu posicionar cada um dos pixels para formar a nova palavra. Seguindo a estética da imagem original, também posicionamos pixels mais claros nas partes inferiores de cada letra para simular uma sensação de profundidade e de relevo (lado direito da Figura 9).

\section{Figura 9 - Placas original e traduzida de cenário no Paint 3D}

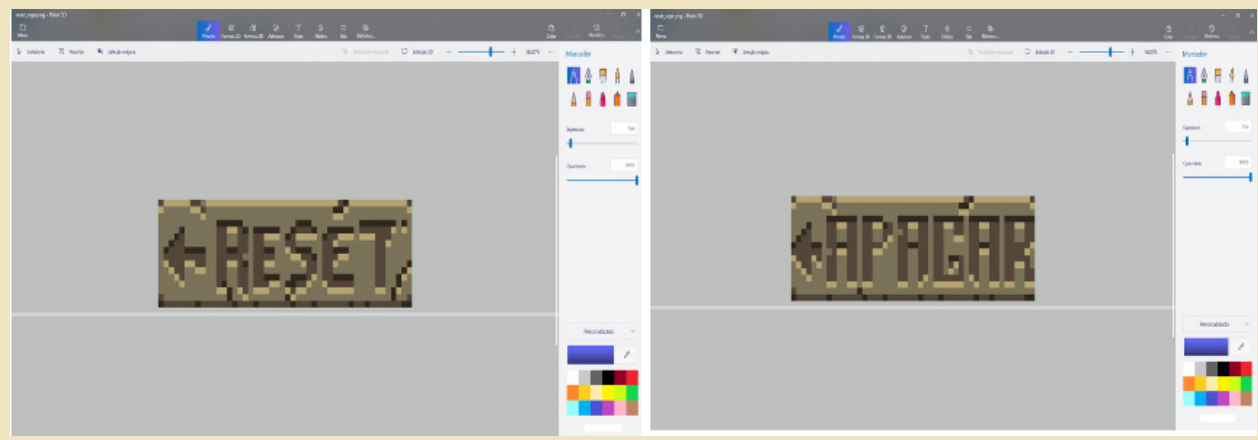

Fonte: arquivos dos autores

O mesmo processo foi repetido com todas as outras placas e imagens de fundo dos cenários, incluindo as três placas contendo os dizeres "Lvl. 5", Lvl. 9" e "Lvl. 13". Essas placas indicam níveis específicos do jogo quando o 
jogador os alcança. Em nossa tradução, utilizamos a palavra "Nível", que é abreviada comumente pela comunidade de jogadores na forma "Nvl.” Já a placa com os dizeres "tutorial" não precisou ser modificada, pois é utilizada de forma igual tanto no inglês quanto no português. A seguir, temos a tela de pontuações do jogo contendo o resultado da tradução da palavra "Reset" (canto direito inferior da Figura 10) e a tela inicial onde o jogador obtém controle do avatar:

\section{Figura 10 - Placa "Reset” no jogo traduzido}

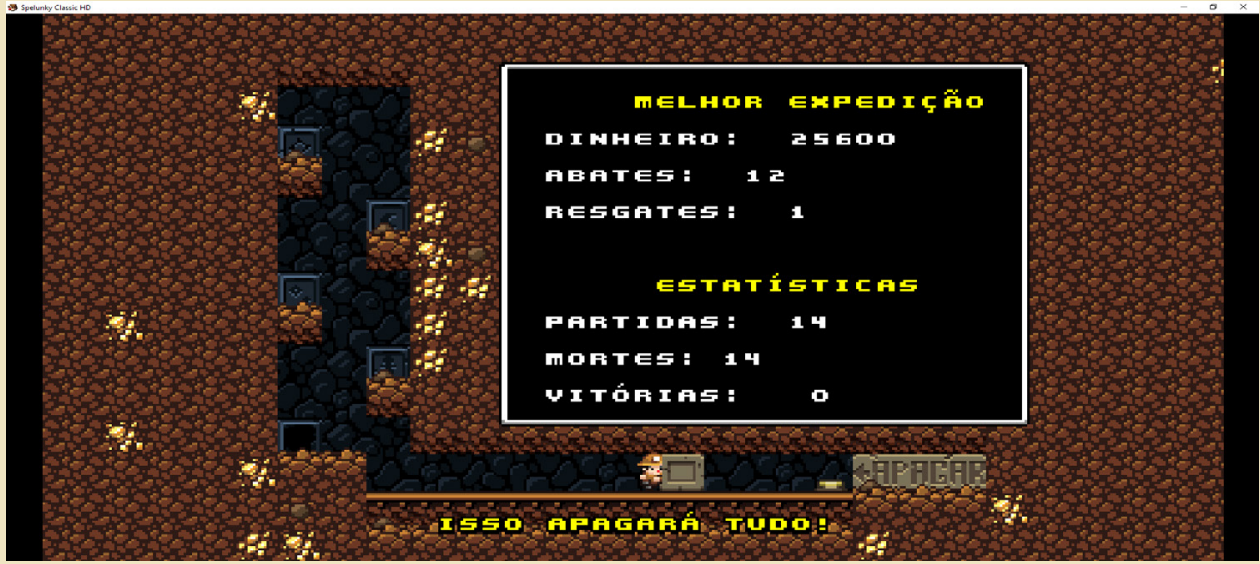

Fonte: arquivos dos autores

Finalizadas estas e outras adequações linguísticas e técnicas, que não serão detalhadas por questões de espaço (cf. FERREIRA, 2021), foi necessária uma nova etapa de testes para verificar o posicionamento das linhas de texto em jogo, já que houve uma mudança significativa no tamanho das letras e no espaço ocupado em tela pelas linhas de texto.

5 Palavras finais

Findos os testes e ajustes, chegamos ao resultado final do processo de localização do Spelunky Classic HD. Os arquivos foram, então, enviados para o desenvolvedor a fim de serem disponibilizados nas plataformas online GitHub e Itch.io. Dessa forma, a comunidade de jogadores brasileiros, 
ou até mesmo de outros países de fala portuguesa, terão acesso ao trabalho aqui produzido e poderão usufruir do jogo em sua língua nativa.

O olhar e a criatividade do tradutor são fundamentais e devem estar presentes nas variadas funções desempenhadas por profissionais envolvidos com o trabalho de localização de um determinado jogo. O Spelunky Classic $H D$ é um jogo com textos relativamente simples, mas, especialmente em jogos mais complexos,

[...] é provável que haverá uma equipe de gerentes, engenheiros, localizadores, terminólogos e tradutores trabalhando em um único projeto. Isso torna necessária uma espécie de "criatividade coordenada". A comunicação, um banco de dados de terminologia e memória de tradução compartilhados e bem mantidos, a revisão e o controle de qualidade podem ajudar a alcançar resultados consistentes e imersivos, mas é necessário muito esforço e tradutores meticulosos que utilizam todos os recursos disponíveis. (CALEK, 2019 apud ESQUEDA, 2020, p. 705, tradução nossa). ${ }^{4}$

O trabalho criativo, em equipe e bem coordenado, é, portanto, um dos pilares da localização na indústria dos jogos eletrônicos. Até mesmo no processo de localização do Spelunky Classic HD, cujo escopo nem de longe se compara ao de grandes jogos da indústria, a colaboração foi extremamente necessária. O contato com o desenvolvedor da modificação, Ivan Yancharkin, durante as etapas mais técnicas relacionadas à programação, foi determinante para os bons resultados alcançados.

Embora jogadores possam ser atraídos por gráficos avançados ou pela história de um jogo, uma localização de baixa qualidade pode frustrar esses jogadores e gerar uma comoção negativa em fóruns da internet ou na mídia especializada. Ao traduzir um jogo eletrônico, necessitamos ter em mente que os textos não devem ser apenas lidos ou ouvidos, eles necessitam transportar o jogador para um mundo virtual, facilitando a jogabilidade e tornando a experiência crível e estimulante (BERNAL-MERINO, 2008).

Por fim, é nesse sentido que as traduções automáticas, ou aquelas realizadas por sistemas tais como Babylon, Bing Microsoft, DeepL, Google Tradutor, My memory, Promt, Systran, Tradukka, Wordlingo ou Yandex,

\footnotetext{
4 Original em inglês: "[...] chances are high that there will be a team of managers, engineers, localizers, terminologists, translators working on a single project. This makes a kind of "coordinated creativity" necessary. Communication, a well-kept, shared terminology database and translation memory, proofreading and QA can help achieve consistent and immersive results, but it does take a lot of effort and very thorough translators who utilize all available resources".
} 
apenas para mencionar os dez mais tradicionais disponíveis no mercado (cf. ESQUEDA, 2021), contribuem muito pouco, ou quase nada, para a tradução e localização de jogos eletrônicos. Diríamos que, até o presente momento, as traduções automáticas não poderão substituir as traduções elaboradas criativamente por tradutores humanos.

\section{Referências}

ARROJO, Rosemary. Oficina de tradução: a teoria na prática. São Paulo: Ática, 1986.

BERNAL-MERINO, Miguel Á. Creativity in the translation of video games. Quaderns de Filologia. Estudis literaris, v. XIII, p. 57-70, 2008. Disponível em: https://roderic.uv.es/bitstream/handle/10550/31595/57.pdf. Acesso em: 03 fev. 2021.

BERNAL-MERINO, Miguel Á. Video games and children's books in translation. The Journal of Specialised Translation, v. 11, p. 234-247, 2009. Disponível em: https://www.jostrans.org/issue11/art_bernal.pdf. Acesso em: 28 mai. 2021.

BERNAL-MERINO, Miguel Á. Translation and localisation in video games: making entertainment software global. Nova York: Routledge, 2015.

CARDOSO, Joel. Cinema e literatura: contrapontos intersemióticos. Literatura em Debate, v. 5, n. 8, p. 01-15, 2011. Disponível em: http://www. revistas.fw.uri.br/index.php/literaturaemdebate/article/view/578. Acesso em: 02 abr. 2021.

CHANDLER, Heather Maxwell; DEMING, Stephanie O 'Malley. The Game Localization Handbook. 2. ed. Sudbury; Mississauga; London: Jones \& Bartlett Publishers, 2012.

CRUZ, Dulce Márcia. A intertextualidade entre os games e o cinema: criando estórias para entretenimento interativo. I Seminário Jogos Eletrônicos, Educação e Comunicação - construindo novas trilhas, mesa 
redonda Narrativas e intertextualidade dos jogos eletrônicos. UNEB, Salvador, p. 1-13, 2005. Disponível em: http://www.comunidadesvirtuais. pro.br/novastrilhas/textos/dulcecruz.pdf. Acesso em: 03 mar. 2021.

DUNNE, Keiran J.; ESQUEDA, Marileide Dias et al. Localização. Belas Infiéis, Brasília, Brasil, v. 9, n. 4, p. 249-270, 2020. DOI: 10.26512/ belasinfieis.v9.n4.2020.26401. Disponível em: https://periodicos.unb.br/ index.php/belasinfieis/article/view/26401. Acesso em: 10 set. 2021.

DUNNE, Keiran J. Localization. In: SIN-WAI, Chan. (ed.). The Routledge Encyclopedia of Translation Technology. Abingdon e Nova Iorque: Routledge, 2015, p. 550-562.

DUNNE, Keiran J. Localization and the (R)evolution of Translation. In: BERMANN, Sandra; PORTER, Catherine (ed.). A Companion to Translation Studies. Chichester: Wiley-Blackwell, 2014. p. 147-162.

ESQUEDA, Marileide Dias. Machine translation: teaching and learning issues. Trabalhos em Linguística Aplicada [online], v. 60, n. 1, p. 282-299, 2021. https://doi.org/10.1590/01031813932001520210212

ESQUEDA, Marileide Dias. Training Translators for Video Game Localization: In Search of a Pedagogical Approach. Revista Brasileira de Linguística Aplicada, v. 20, n. 4, p. 703-731, 2020. DOI: https://doi. org/10.1590/1984-6398202016045 Disponível em: http://www.scielo.br/ scielo.php?script=sci_arttext\&pid=S1984-63982020000400703\&lng=en\&n rm=iso. Acesso em: 30 abr. 2021.

FERREIRA, Gabriel Albuquerque. Spelunky Classic HD em pt-BR: desafios da tradução e localização de jogos eletrônicos. 2021. 59 f. Trabalho de Conclusão de Curso (Graduação em Tradução) - Universidade Federal de Uberlândia, Uberlândia, 2021.

FURLAN, Mauri; ALTHOFF, Gustavo. Alea iacta est: localização de games e outros jogos. Scientia Traductionis, n. 15, p. 1-3, 2014. Disponível em: https://periodicos.ufsc.br/index.php/scientia/issue/archive.Acesso em: 02 mai. 2021. 
GALHARDI, Rafael. Localização de Jogos: Libertando a Imaginação com Tradução Restrita, de Carmen Mangiron e Minako O’Hagan. In-Traduções, v. 5, n. esp.- Games e Tradução, p. 68-85, out 2013. Disponível em: http:// stat.entrever.incubadora.ufsc.br/index.php/intraducoes/article/view/2511. Acesso: 28 mai. 2021.

MANGIRON, Carmen; O’HAGAN, Minako. Game Localisation: Unleashing Imagination with 'Restricted' Translation. The Journal of Specialised Translation, v.6, p.10-21, 2006. Disponível em: http://www. jostrans.org/issue06/art_ohagan.pdf. Acesso em: 28 mai. 2021.

MUSSA, Ivan. Desembrulhando Verdades. Entre.Meios: Revista da PósGraduação em Comunicação da PUC-RJ, Rio de Janeiro, v. 12, p. 1-13, 2016. Semestral. Disponível em: http://entremeios.com.puc-rio.br/media/ t4_v12.pdf. Acesso em: 02 mai. 2021.

O'HAGAN, Minako; MANGIRON, Carmen. Game Localization: Translating for the global digital entertainment industry. John Benjamins Publishing, 2013.

SARMENTO, Rowan; OLIVEIRA, Jéssica; MAFRA, Victor; NEVES, André. Características Empáticas Humanas em Personagens Clássicas de Videogame Pixel Art. In: ENCONTRO POTIGUAR DE JOGOS, ENTRETENIMENTO E EDUCAÇÃO, 2, 2016, Natal. Anais... Natal: UFRN, 2016. Artigos, p. 55-66. Disponível em: http://ceur-ws.org/Vol1754/EPoGames_2016_AC_paper_15.pdf. Acesso em: 08 maio 2021.

SILBER, Daniel. Pixel Art for Game Developers. CRC Press, 2016.

SOUZA, Ricardo Vinicius Ferraz. Venuti e os Videogames: o conceito de domesticação/estrangeirização aplicado à localização de games. InTraduções, v. 5, n. esp, p. 51-67, 2013. Disponível em: http://stat.ijie. incubadora.ufsc.br/index.php/intraducoes/article/viewFile/2519/3141. Acesso em: 28 mai. 2021.

THOMPSON, Tommy. With Fate Guiding My Every Move: The Challenge of Spelunky. In: Foundation of Digital Games Conference Series. Proceedings... p. 1-8, 2015. Disponível em: http://www.fdg2015.org/ proceedings.html. Acesso em: 27 mai. 2021. 
ZAVAGLIA, Adriana; RENARD, Carla M. C.; JANCZUR, Christine. A tradução comentada em contexto acadêmico: reflexões iniciais e exemplos de um gênero textual em construção. Aletria: Revista de Estudos de Literatura, v. 25, n. 2, p. 331-352, 2015. DOI: https://doi.org/10.17851/23172096.25.2.331-352 